\title{
Initiation of Complementary Feeding Practice And Associated Factors Among Mothers Having Children 6-23 Month of Age, In Meket Woreda, North Wollo Ethiopia, 2020: A Multicenter Community -Based Cross-Sectional Study.
}

Dejen Feleke ( $\boldsymbol{\sigma}$ dejengetaneh38@gmail.com )

Debre Tabor University

Abebu Yasin Tadesse

Debre Tabor University

Ermias Sisay Chanie

Debre Tabor University

Amare Kassaw Wolie

Debre Tabor University

Sheganew Fetene Tassew

Debre Tabor University

Gashaw Mehiret Wubet

Debre Tabor University

Agimasie Tigabu Demelash

Debre Tabor University

Tadela Dires

Debre Tabor University

Eshtie Molla Alemu

Debre Tabor University

Mekalem Mamuye Azanaw

Debre Tabor University

Masresha Asmare Techane

University of Gondar

Sisay Shewasinad Yehualashet

Debre Tabor University

Eyasu Alem Lake

Wolaita Sodo University

Birhanu Wondmieneh Demissie

Wolaita Sodo University

Habtamu Shimeles Hailemeskel

Debre Tabor University 


\section{Sintayehu Asenakew Alemayehu}

Debre Tabor University

\section{Research}

Keywords: Complementary feeding, Children, Meket, Ethiopia

Posted Date: July 26th, 2021

DOl: https://doi.org/10.21203/rs.3.rs-703787/v1

License: (1) This work is licensed under a Creative Commons Attribution 4.0 International License. Read Full License 


\section{Abstract}

Introduction: improving the infant and young child feeding practices in children aged 0-23months is critical. It is necessary to improved infant and young child health, nutrition, and development. Infant and under five mortality rate in Ethiopia are $43 / 1,000$ and $55 / 1,000$ live births respectively.

Objective: To assess Initiation of CF practice and associated factors among mothers with children aged 6-23months.

Methods: a multicenter Community based cross sectional study was conducted among 416 mother-infant pairs of 6-23 months in Meket Woreda, Northwest Ethiopia from March 20-June 30, 2020. Bivariate and multivariable logistic regeration model was fitted to identify factors associated CF Practice. P-value less than 0.05 considered as significance.

Result: Among 416 mothers with children aged 6-23 months, 76.4\% mothers started giving CF timely at recommended age of 6 month of child age. Advised About CF during ANC follow up [AOR=0.03; $95 \% \mathrm{Cl}$ : $0.003-$ 0.356], Child delivered place at a health facility [AOR=0.07; $95 \% \mathrm{Cl}: 0.0-0.619]$, mothers take family planning [AOR $=0.049 ; 95 \% \mathrm{Cl}: 0.011-0.23]$, give additional diet the $1^{\text {st }} 6$ month [AOR $=0.035 ; 95 \% \mathrm{Cl}: 0.009-0.137$ ] and $\mathrm{BF}$ makes appearance $[\mathrm{AOR}=0.064 ; 95 \% \mathrm{Cl}: 0.003-0.687]$ were found to be independent predictors of $\mathrm{CF}$ practice.

Conclusion and Recommendation: About $23.6 \%$ of mothers were not initiated CF practice their children at recommended age of 6 month. This would have negative implication on the health of infants and young children. Health professionals should focus on advising and counseling mothers on appropriate CF during prenatal, delivery, post natal, and immunization services.

\section{Summary Statement}

What is already known about this topic? Already known in this topic scientific background of complementary feeding and Malnutrition has been responsible for 60 percent of the 10.9 million deaths annually among children under five, globally. Over two-thirds of these deaths, which are often associated with inappropriate CF practice and infectious disease, occur during the first year of life. The majority of these deaths occur in subSaharan Africa and the major contributors to their death are poor optimal BF and CF. It is estimated that sub optimal CF in the first six months of life results in 1.4 million deaths and 10 percent of the disease burden in children younger than five years.

What this paper adds: this paper adds to know among 416 mothers with children aged 6-23 months, 76.4\% mothers started giving complementary feeding timely at recommended age of 6 month of child age. Advised About CF during ANC follow up [AOR=0.03; $95 \% \mathrm{Cl}$ : 0.003-0.356], Child delivered place at a health facility [AOR $=0.07 ; 95 \% \mathrm{Cl}: 0.0-0.619]$, mothers take family planning [AOR= $0.049 ; 95 \% \mathrm{Cl}: 0.011-0.23]$, give additional diet the 1 st 6 month [AOR $=0.035 ; 95 \% \mathrm{Cl}: 0.009-0.137]$ and $\mathrm{BF}$ makes appearance [AOR $=0.064 ; 95 \% \mathrm{Cl}$ : 0.0030.687] were found to be independent predictors of complementary feeding practice. 
The implications of this paper: the implementation of the strategy has remained inconsistent and health messages lacked focus on factors that influence maternal practice excluding infants from getting CF practice. This study tries to assess the practice of these mothers about the prevalence of CF to their infants. If this down sides continues the number of infants death will increase because of Malnutrition particularly at the infant stage of development. Findings of this study had helpful to policy makers, program designers, academic program designers, and communities' health extension workers who were working on this area to understanding the level of $\mathrm{CF}$, identify factors affecting $\mathrm{CF}$, set interventions, and used as resources for other studies which were conducted in this issue in the future. Therefore, the aim of this study will be to assess the prevalence of CF practice and its associated factors among mothers with children aged 6-23months in Meket Woreda, Northwest Ethiopia, 2020. Again, this finding is used as one input to reduce child mortality and finally to achieve the sustainable development goal. The result obtained from the study was important for responsible bodies and for the development of interventions against this problem. This study is also used for baseline data for further research.

\section{Background}

Complementary feeding refers when breast milk alone is no longer sufficient to meet the nutritional requirements of infants; therefore it means the feeding of solid, semi-solid or soft foods in addition to breastfeeding. According to the World Health Organization, complementary feeding should be introduced timely at 6 months of age, sufficient meal frequency and diversity of diet. The transition from exclusive breastfeeding to family foods which covers the period from 6-23 months of age, even though breastfeeding may continue to two years of age and beyond (1).

Complementary feeding (CF) should be timely (start receiving from 6 months onward) and adequate (in amounts, frequency, consistency, and using a variety of foods). The foods should be prepared and given in a safe manner and be given in a way that is appropriate (foods are of appropriate texture for the age of the child) and applying responsive feeding following principles for psychosocial care $(2,3)$.

From the sixth month onward, complementary foods should be of variety, and balanced mixtures of food items containing cereals, foods of animal and vegetable origin, and fat should be offered. Only a varied diet guarantees the supply of micronutrients, enhances good eating habits, and prevents the development of anorexia caused by monotonous foods. Grain products (whole grain) can serve as sources for carbohydrates, fibers, and micronutrients such as thiamin, niacin, riboflavin, and iron. Protein-rich foods, such as meat, poultry, fish, egg yolks, cheese, yogurt, and legumes, can be introduced to infants between 6 and 8 months of age (35). Complementary foods usually are of two types, thus are commercially prepared infant foods bought from the market and homemade complementary foods, which are prepared at household level by the caregivers following traditional methods $(6,7)$.

$\mathrm{CF}$ is important during the period of 6-23 months since it is also regarded as "critical window" for a child's health, growth, and development. A review by reported that CF should be timely starting at 6 months, adequate (in amount and variety) (8).

An assessment of the CF practices among different sub populations is important for understanding the meal frequencies and diversity of diets of children at 6-23 months. 
CF practices are still poor in most developing countries and are even worsening in some of them. The achievement of universal coverage of optimal breastfeeding could prevent $13 \%$ of death occurring in under-five years' children globally. While, appropriate CF practice would result in an additional $6 \%$ reduction in under-five mortality (9).

Malnutrition has been responsible for 60 percent of the 10.9 million deaths annually among children under five, globally. Over two-thirds of these deaths, which are often associated with inappropriate CF practice and infectious disease, occur during the first year of life (1). The majority of these deaths occur in sub-Saharan Africa and the major contributors to their death are poor optimal BF and CF (10). It is estimated that sub optimal CF in the first six months of life results in 1.4 million deaths and 10 percent of the disease burden in children younger than five years (11).

Globally, minimum meal frequency is at $52.2 \%$, minimum dietary diversity is $29.4 \%$ and minimum acceptable diet is at $16 \%$ (12). Uganda has got a national policy on infants and young child feeding, although considerable progress has been made over the last few decades towards the implementation of programmes designed to promote EBF;CF practice has lagged behind over the same period. EBF is at $65.7 \%$ while CF is at $14 \%$ (13). Progress in CF has been hampered mainly due to the lack of standard indicators to assess for CF previously not until 2008 when core indicators were introduced (1). Studies done in Nigeria Prevalence of Initiation of CF Were 54\%(14) ,and Studies conducted in Iran, Kenya prevalence of initiation of CF were, $83.6 \%$, $85.4 \%$ Respectively $(15,16)$.

In Ethiopia, the rate of stunting, underweight and wasted among under-5 children were $37 \%, 21 \%$ and $7 \%$ respectively and alsoit is one of the countries with the highest infant and child mortality rates in the world, Infant mortality and under five mortality rates are 43/1,000 and 55/1,000 live births respectively. CF practices are critical public health measures to reduce and prevent morbidity and mortality in young children in order to achieve the Sustainable Development Goal 4 [(17),(18)]. About $50 \%$ of child death is related to malnutrition which can be preventable through appropriate CF practice including breast feeding. Breast milk and CF could prevent $13 \%$ and $6 \%$ of under 5 child mortality respectively (19). Analysis of demographic and health survey data on infant and young child feeding practice in Ethiopia 2019 for IYCF compression showed that, practice of CF Age 6-9 months were71.2 (20). In Amhara region of Ethiopia practice of CF and minimal dietary diversity is $34.6 \%$ and $2.1 \%$ respectively(21). Studies done in different area of Ethiopia Initiation of CF practice were in Hiwot Fana Specialized Hospital, Eastern Ethiopia 60.5\% (22), in Benishangul Gumuz Region, Ethiopia 61.8\% (23), in Addis Ababa, Ethiopia 83\% (24), in Northern Ethiopia 15\% (25), in Halaba Kulito town, Southern Ethiopia 57.8\% (26) in Southern Ethiopia97.6 \% (27), in Northern Ethiopia 62.8\%(28), in Sodo town, Southern Ethiopia $71.2 \%$ (29), in rural Soro district of Southwest Ethiopia 34.3\% (30). Institution based cross sectional study in Gondar town among infant and young children showed that $89.5 \%$ of mothers followed the recommended way of infant feeding practice(31).Another study Lasta District About $43.5 \%$ of mothers was not feeding their children complementary food appropriately (32).

However, the implementation of the strategy has remained inconsistent and health messages lacked focus on factors that influence maternal practice excluding infants from getting CF practice. This study tries to assess the practice of these mothers about the prevalence of CF to their infants. If this down sides continues the number of infants death will increase because of Malnutrition particularly at the infant stage of development. 
However, no studies were documented about prevalence of complementary feeding of infants in the study area. To make some contribution to Meket Woreda and its surrounding Keble's an attempt has been made to investigate the prevalence of complementary feeding practice and its associated factors among mothers with children aged $6-23$ months.

Hence, this study is very important to assess the prevalence of Initiation of complementary feeding practice and its associated factors among mothers with children aged 6 -23months in Meket District, North Wollo Ethiopia, 2020 (See Fig. 1: Conceptual framework).

\section{Methods \& Materials}

\section{Study Area and Period}

The study was conducted in selected Keble of Meket Woreda Northwest, Ethiopia. Meket Woreda is the largest Woreda of the North Wollo zone. It is located about $205 \mathrm{~km}$ away from Bahir Dar, regional capital city and 709 $\mathrm{km}$ far from Addis Ababa, the capital city of Ethiopia. The total population is 243,549 people of which 119339 are males and 124210 females and there are 32977 under five children, 12299 under two years' children and 10692 children's age 6-23month in the Woreda There are 2 urban and 34 rural Keble in Meket Woreda. There is 1 primary hospital, 7 governmental health centers and 36 health posts in the Woreda (33). The study was conducted from June 2020 to December 2020.

\section{Study design and participants characteristics}

Community based Multi central cross-sectional study design was conducted. All mother-child pairs from 6-23 months in Meket Woreda, who residing for more than six months were Source population. Sample mother-child pairs from 6-23 months in Meket Woreda who full fill the inclusion criteria were the study participants this study.

\section{Sample size determination}

Sample size was calculated using single population proportion formula by assuming $p=$ prevalence of CF practice of mothers $56.5 \%$ taken from the study conducted in Lasta District (34), Z = 1.96 and $D=$ precision (marginal error) $=5 \%$, sample size was calculated as Follows

$$
\mathrm{n}=\frac{\left(\mathrm{Z}_{\mathrm{a} / 2}\right)^{2} \mathrm{P}(1-\mathrm{P})}{\mathrm{d}^{2}}
$$

Where $\mathrm{n}=$ Sample size needed

$z=$ Standard normal variable at $95 \%$ confidence level (1.96)

$\mathrm{p}=$ the prevalence of CF in Lasta District (0.565)

$d=$ Margin of error (0.05) 
$\mathrm{Z} \mathrm{a} / 2=$ Value of standard normal distribution corresponding to significant level of alpha (a) 0.05 which is 1. 96.

Taking 10\% (13) non-response rate the final sample size was NRR $=38$ then $38+378=416$.

\section{Sampling procedure}

There are 36 kebeles in the woreda and cluster sampling was used to take the appropriate sample. Initially, Meket Woreda were classify into 36 clusters based on the number of kebeles. Then nine clusters were selected randomly by lottery method. The households were identified by health extension workers (Pre-survey was conduct before the actual day of data collection to determine which households have the target mother-child pairs). The data collection was started at one of the selected kebele by lottery method and continues to next kebele. The first household was selected randomly and the subsequent household was selected according to the principle of next nearest household. Households in the clusters were visited until all Proportion samples included. When two or more eligible mothers to child pairs were found, only one was included by lottery method. For eligible participant that was not found at home during data collection, the interviewers was revisiting the household three times at different time intervals and when interviewers failed to get the eligible participant, the household was registered as non-response.

\section{Operational definition}

- Breast feeding: is a means of infants and young children feeding with milk from a woman's breast.

- Initiation of complementary feeding at 6 months of age: started CF (start (initiate) additional foods to child besides breast milk) at 6 months child $(1,24,26)$.

- Early introduction of CF: Proportion of breastfed children 6-23 months of age who had been introduced CF before 6 months of age (29).

- Exclusive breast feeding: refers to feeding infants only with breast-milk up to 6 months.

- Infant and young child feeding: is feeding a child until two years of age.

- Mother's knowledge complementary feeding: Mothers IYCF knowledge was determined using knowledge item questions, Accordingly, respondents were asked about IYCF item questions Then, if the mothers correctly answer $50 \%$ or more of the above knowledge questions, she will considered as having a good knowledge, otherwise, below $50 \%$ will be a poor knowledge (23).

- Complementary feeding: is the process of starting additional foods when breast milk alone is no longer sufficient to meet the nutritional requirements of infants (26).

\section{Data collection tools and techniques}

\section{Data collection tools}

Data was collected using a pre-tested and structured interviewer-administered questionnaire, which was adapted from UNSF and others different Articles (19, 22, 24, 27-30, 32, 35-39), (40). The questionnaire was 
prepare in the English version and it translated to the local language (Amharic which was used to collect the data). The questionnaire has fifty nine questions and four parts: socio-demographic and economic characteristics assessment status, maternal obstetric and health care service related assessment, knowledge and pattern of complementary feeding 6-23months factors and Measuring Maternal Attitudes towards Complementary Infant Feeding related Assessment.

\section{Data collection techniques}

A total of two diploma nurses as data collector and two BSc nurses as a supervisor (who have an experience of data collection) were selected. After briefly presenting the study purpose and getting oral consent from each mother with an eligible infant, data collectors interviewed participants.

\section{Data quality control}

The quality of the data was assured by pre-testing the questionnaire on $5 \%$ of the sample (31 mothers with an eligible infant) in Flakit Keble prior to the start of the actual study to test the fitness of the questionnaire for the study settings. Training about the data collection tool as well as data collection procedures (ways of approaching the eligible mothers and how to obtain permission for an interview) was give to data collectors and supervisors for a total of one day prior to the data collection process.

The objectives of the study were clearly explained to the data collectors as well as supervisors. The respondents were give brief orientation before they are interviewed and supervision was done at the spot by the supervisors. Throughout the course of the data collection, interviewers was supervised at each site, regular meetings was held between the data collectors, supervisor, and the principal investigator to discuss the problem arising in each interview, and detailed feedback was provided to the data collectors.

In addition, the collected data was check daily for its completeness, accuracy, and clarity by supervisors. The principal investigator was checked every questionnaire before data entry. Data was kept in the form of a file in a private secured place.

\section{Data processing and analysis}

After checking the completeness of the data, it was entered into Epi data version 3.1.1, and then; it was exported to SPSS Version 20 for analysis. Descriptive analysis was due by computing proportions and summary statistics. The association between each independent variable and the outcome variable will assess by using binary logistic regression. All variables with $P \leq 0.2$ in the bivariate analysis were included in the final model of multivariable analysis in order to control all possible confounders. Adjusted odds ratio along with $95 \% \mathrm{Cl}$ will computed and P-value $\leq 0.05$ will consider declaring factors that have statistically significant association with ICF by using multivariable analysis in the binary logistic regression. The goodness of fit was tests by Hosmer-Lemeshow statistic test. Finally; the result is presented in the form of texts, tables and graph.

\section{Results}

\section{Socio-Demographic Characteristics of Mothers}


Among 416 sampled mothers, 416 were successfully included in the study making the response rate of $100 \%$. The median age of mothers was 29 years with inter quartile range (IQR) being 8 . Three hundred seventy three (89.7\%) were orthodox by religion while others (8.9\%) Muslim, (1.4\%) protestant and most of them (96.9\%) belong to the Amhara ethnic group. Concerning the educational status of mothers, $123(29.6 \%)$ respondents were Unable to read and write the other151 (36.3\%) had attended formal school. The majority of mothers, 350 (84.1\%), were married and 26 (62.5\%) were house wives by occupation. More than a half, 244 (58.7\%), of mothers earned an average monthly income was between in the range of 500-3000 Ethiopian Birr. Husbands of $192(46.1 \%)$ mothers had attended formal education. The median age of children was 12 months with IQR being 8, sex of the children 219 (52.6\%) male and 197 (47.4\%) were Female (See Table-1).

\section{Obstetrics and Health Service Related Variables}

The majority of mothers, 305 (73.3\%), had antenatal care follow up during the last pregnancy. From respondents 51 (12.3) had only first ante natal care follow up and 32.2\% (134/416) of mother had at least four visits as recommended. About 270 (64.9\%) of mothers give birth their last child at health institution.

Approximately 248 (59.6\%) had received postnatal care (PNC) at least once (See Table-2).

\section{Complementary Feeding Knowledge and Practices}

In this study, it was found that majority (82.9\%) of mothers had ever practiced breastfeeding exclusively. Approximately $80 \%$ (333/416) of mothers had satisfactory knowledge and the rest $19.7 \%$ had poor knowledge about started complementary feeding. About 32.5\% (135/416) of mothers had supportive attitude while the rest $67.5 \%$ had no supportive attitude towards complementary feeding. Cereal and Milk product were the most commonly taken food items of the children (42.3\% \& 32.2\%) respectively. Legumes and nuts (9.1\%), vitamin-A rich foods (2.4\%), other fruits and vegetables (4.1\%) and egg (8.2\%) Generally the rates of different food groups offered were uniformly lower in the 6-23 months child age group. The $76.4 \%(95 \% \mathrm{Cl}: 318 / 416)$ of mothers introduced complementary feeding at 6 months age of the children as per recommended. Only $7(1.7 \%)$ mothers introduced complementary feeding early before 6 month, $8(1.9 \%)$ mothers initiated late after 6 month and 83 (20\%) mothers did not start complementary feeding at all (See Table-3), (Figs. 2 and 3).

\section{Attitudes of Mothers on Complementary Infant Feeding}

Concerning the attitudes of mothers towards complementary infant feeding most respondents (30.3\%) were not agreed with the item that states about complementary foods make the infants fat, and also (22.6\%) shows the strong agreement on the item the it makes their infants fat. The majority of the respondents (39.7\%) responded that even though they have sufficient money to buy complementary foods they prefer to suffer themselves on breastfeeding their infants but $15.3 \%$ of the participants agree to buy complementary foods than suffering themselves by breast feeding. This implies that for these mothers breast feeding is not based on the interest but only the shortage of money to buy complementary foods make them to breast feed.

Regarding the early initiation of complementary foods $38.4 \%$ of the respondents agreed that just after birth they introduced their infants with complementary foods. The other number $(17.8 \%)$ of the participants replied that even if their breast does not have sufficient milk they never introduced their new born infants with 
complementary foods. On the process of providing complementary foods the vast majority of the respondents (35.8\%) reported that they like the item stated as since other help them in providing complementary foods because others can help them in feeding it. Others $(15.6 \%)$ said that were not agreed with this idea. Concerning the physical appearance and complementary foods of the respondents, $(14.6 \%)$ said that since breastfeeding makes our appearance thin we prefer to give complementary foods. Others $(27.2 \%)$ replied that that they did not give complementary foods even breast feeding make their appearance thin. This indicates that mothers in this particular culture have strong desire to breast feed than complementary feeing practice. Concerning the issue of complementary foods with health effect, most participants $(50.7 \%)$ revealed that complementary foods make their infants healthy and strong. But a few (11.1\%) of the respondents reported that complementary foods cannot make their infants healthy and strong.

Lastly $15.6 \%$ of the participants agreed that instead of breast milk after six months, complementary foods are preferable or should be given more weight (Table-4).

\section{Prevalence of Initiation of Complementary Feeding Practice}

In this Study among 416 mothers with children aged 6-23 months, $76.4 \%$ mothers started giving complementary feeding timely at recommended age of 6 month of child age.

\section{Factors Found Associated with initiation of Complementary Feeding Practice}

After applying Bivariate and multiple logistic regressions, five variables were found to be significantly associated with initiation of complementary feeding practice. These were mothers had family planning [AOR = 0.049; $95 \% \mathrm{Cl}: 0.011-0.23$, mothers who had Antenatal care follow up [AOR $=0.03 ; 95 \% \mathrm{Cl}: 0.003-0.356]$, Child delivered place at a health facility [AOR $=0.07 ; 95 \% \mathrm{Cl}: 0.0-0.619]$, give additional diet the 1 st $6 \mathrm{month}$ [AOR $=$ $0.035 ; 95 \% \mathrm{Cl}: 0.009-0.137$ ] and were $\mathrm{BF}$ makes appearance [AOR $=0.064 ; 95 \% \mathrm{Cl}: 0.003-0.687$ ] more likely to initiate complementary feeding to their children (See Table-5).

\section{Discussion}

In this Study among 416 mothers with children aged 6-23 months, $76.4 \%$ mothers started giving complementary feeding timely Mothers Having Children 6-23 Month of Age, In Meket Woreda, North Wollo Ethiopia 2020.

This study showed that 76.4\% of mothers in Meket Woreda, North Wollo Ethiopia Mothers Having Children 623 Month of Age. This finding was in line with a study conducted Analysis of demographic and health survey data on infant and young child feeding practice in Ethiopia 2019 for IYCF compression showed that, practice of CF Age 6-9 months were 71.2\%(20). In Ethiopia practice of CF in Addis Ababa, Ethiopia 83\% (24), in Sodo town, Southern Ethiopia $71.2 \%$ (29). The similarity of this study could be the study design and socio-cultural resemblance among society on infant feeding practices. Studies conducted in Iran, Kenya prevalence of initiation of CF were, $83.6 \%, 85.4 \%$ Respectively $(15,16)$. The similarity of this study could be the study design on infant feeding practices. 
However, the result of this study was much lower than the study done in Southern Ethiopia $97.6 \%$ (27). Institution based cross sectional study in Gondar town among infant and young children showed that $89.5 \%$ of mothers followed the recommended way of infant feeding practice (31). The probable reason for the above difference in rates could be variation in information disseminations on child feeding practice.

This result was higher as compared with other similar studies such as on research done In Amhara region of Ethiopia practice of CF and minimal dietary diversity is $34.6 \%$ and $2.1 \%$ respectively (21). Studies done in different area of Ethiopia Initiation of CF practice were in Hiwot Fana Specialized Hospital, Eastern Ethiopia $60.5 \%$ (22), in Benishangul Gumuz Region, Ethiopia 61.8\% (23), in Northern Ethiopia 15\% (25), in Halaba Kulito town, Southern Ethiopia 57.8\% (26), in Northern Ethiopia 62.8\% (28), in rural Soro district of Southwest Ethiopia $34.3 \%$ (30). Another study Lasta District About $43.5 \%$ of mothers was not feeding their children complementary food appropriately (32).

According to the World Health Organization, CF should be introduced timely at 6 months of age, sufficient meal frequency and diversity of diet. At 6 months breast milk provides 60 percent of the total dietary energy requirement and the 40 percent should be derived from complementary foods (1). The magnitude of CF practice is unacceptably low in the studies conducted in different countries of the world like $32 \%$ in India(41), $37 \%$ in Zambia(42), and $15.7 \%$ in Ghana(43). These studies also indicated low minimum dietary diversity. Studies done in Nigeria Prevalence of Initiation of CF Were 54\% (14). The reason why these discrepancies happened may be due the presence of variations in geographical location, socio-cultural practices, policies and economic status.

In multiple logistic regressions significantly associated with initiation of complementary feeding practice. These were mothers had family planning $[A O R=0.049 ; 95 \% \mathrm{Cl}: 0.011-0.23]$, mothers who had Antenatal care follow up [AOR $=0.03 ; 95 \% \mathrm{Cl}: 0.003-0.356$ ], Child delivered place at a health facility [AOR $=0.07 ; 95 \% \mathrm{Cl}: 0.0-$ 0.619], give additional diet the 1 st 6 month [AOR $=0.035 ; 95 \% \mathrm{Cl}: 0.009-0.137$ ] and were $\mathrm{BF}$ makes appearance $[\mathrm{AOR}=0.064 ; 95 \% \mathrm{Cl}: 0.003-0.687]$ more likely to initiate complementary feeding to their children.

this finding was supported by the study done in n Lalibela District, Northeast Ethiopia, Antenatal care, and institutional delivery were reported to be significantly associated with appropriate complementary feeding (35). A high frequency of antenatal visits (4+) was associated with appropriate complementary foods as compared to mothers who did not attend antenatal care, these findings suggest that mothers who attend antenatal care have better access to health services such as nutrition counseling and respond to health information messages on CF. Similarly, this might be due to the fact that home delivered mothers would not have sufficient information about recommended child feeding practices and they are more influenced by communities' inappropriate child feeding practices(IACFP) and also study conducted on the risk factors of poor CFP found delayed maternal postnatal checkup as a significant factor that increased the odds of not meeting the criteria for ACF (44).

According to the study done in Benshangul, Ethiopia, mothers postnatal checkup, showed significant associated with CF $[$ AOR $(95 \% \mathrm{Cl})=1.68(1.15,2.45)](23)$. Study conducted in Adiss Abeba Ethiopia, mother's attend ANC, Made a plan for reaching the facility during labor, Place of delivery at Health facility, Postnatal care attendance [AOR $(95 \% \mathrm{Cl})=0.89(0.24,3.34)]$, [AOR $(95 \% \mathrm{Cl})=0.69(0.37,1.26)]$, [AOR $(95 \% \mathrm{Cl})=0.32$ $(0.12,0.82]$, [AOR $(95 \% \mathrm{Cl})=0.75(0.46,1.23)]$, showed significant associated with CF Respectively (24). Study 
conducted in Halaba Kulito town,Southern Ethiopia, Place of delivery, at Health Center, Hospital [AOR (95\% CI) $=2.36(0.67,8.31)]$, [AOR $(95 \% \mathrm{Cl})=2.79(0.66,11.86)]$, showed significant associated with CF Respectively (26). Study done in Arsi Negele, Southern Ethiopia, Place of delivery, Health facility, Attended ANC, Attended PNC, Attended HDAs $(1-5)$ [AOR $(95 \% \mathrm{Cl})=1.37(0.74-2.55)]$, [AOR $(95 \% \mathrm{Cl})=1.65(0.11-24.85)],[\mathrm{AOR}(95 \% \mathrm{Cl})=$ $1.86(0.79-4.36)]$, [AOR $(95 \% \mathrm{CI})=1.61(0.70-3.68)]$, showed significant associated with CF Respectively (39).

Study conducted in Sodo town, Southern Ethiopia, mothers follow ANC, mothers follow PNC, Place of delivery, Health facilities [AOR $(95 \% \mathrm{Cl})=3.30(1.21-8.99)]$, [AOR $(95 \% \mathrm{Cl})=0.92(0.62-1.40)],[\mathrm{AOR}(95 \% \mathrm{Cl})=$ 3.15(1.61-6.17)], showed significant associated with CF Respectively (29).

Study conducted in Mekelle Town, Northern Ethiopia, Source of Information, mothers follow ANC, mothers not follow PNC, Place of delivery, Health facility, [AOR $(95 \% \mathrm{CI})=2.845(1.240,6.528)]$, ,[AOR $(95 \% \mathrm{Cl})=0.860$ $(0.492,1.505)]$ showed significant associated with CF Respectively (28). Study conducted in Tahtay Maichew district, northern Ethiopia, Mother follow ANC, , mothers not follow PNC, [AOR (95\% Cl) = 1.58 (0.60-4.21)], [AOR $(95 \% \mathrm{Cl})=1.15(0.94-1.41)]$ showed significant associated with CF Respectively (37). Study conducted in Soro district, South Ethiopia, Institutional delivery, $[$ AOR $(95 \% \mathrm{Cl})=0.79(0.21,2.99)$ ], showed significant associated with CF (30).

\section{LIMITATIONS OF THE STUDY}

Due to retrospective nature of the study there might be a recall bias.

\section{Conclusion}

Almost two-third of mothers initiated complementary feeding at sixth month of child age that is relatively higher prevalence than other countries. In order to reduce the high infant mortality this level has to be increased since $23.6 \%$ of the mothers are still not starting complementary feeding at six months. This would have negative implication on the health of infants and young children. There was statistically significant association of initiation of complementary feeding practices with mothers' advised About CF during ANC follow up, child delivered place at a health facility, take family planning, give additional diet the 1 st $6 \mathrm{month}$, and mothers' think BF makes appearance, were factors that can increase appropriate complementary feeding practice.

\section{RECOMMENDATION}

\section{For Woreda health bureau and zone health office}

Nutrition education should be delivered in good manner by giving especial emphasis on child feeding practices through health extension program and nutrition advocacy through the use of mass media. Health

Extension workers should be trained to provide health services at community level to reduce the prevalence of communicable disease and to improve the coverage of timely introduction of complementary feeding. It is better to assign nutrition professionals at health institution and Woreda health office level. It is better to strengthen inter sectorial involvement of organizations working on nutrition promotion to realize nutrition 
interventions. Health professionals should focus on advising and counseling mothers on appropriate and timely initiation of complementary feeding during prenatal, delivery, postnatal, and immunization services.

Developing motivational factors for mothers who practice complementary feeding appropriately could be promotion (advertising) of complementary feeding.

\section{To the researchers}

Further research is needed to identify related factors of timely introduction of complementary feeding especially qualitative aspects, i.e. attitude and beliefs of the community related to timely introduction of complementary feeding.

\section{Abbreviations}

ACF: Appropriate complementary feeding, AOR: Adjusted odd ratio, BF: Breast feeding, BM: Breast milk, BSC: Bachelor of Science, CF: Complementary Feeding, IACFP: Inappropriate child feeding practices, IYCF: Improving infant and young child feeding, MDD: Minimum dietary diversity, MSC: Master of Science, SPSS: statistical package for social sciences, W.H.O: World Health Organization

\section{Declarations}

\section{Consent to publication}

Not applicable

\section{Availability of data and materials}

Data will be available upon request from the corresponding author.

\section{Competing interests}

The authors declare that they have no competing interests.

\section{Ethical approval and consent to participate}

Ethical clearance was obtained from the ethical review committee of Debre Tabor University, College of Health Sciences. Before the beginning of data collection, permission letter was obtained from Meket Woreda health bureau and from each kebele administration. Then, the participants of the study were informing about the purpose of the study, the importance of their participation, and their right to withdraw at any time. Verbal informed consent was obtained prior to data collection. Mothers who are not practice ICF at 6 months during the data collection period was advised regarding to infant feeding. All the information given by the respondents was used for research purposes only and confidentiality and privacy was maintained by omitting the name of the respondents during data collection procedure. 


\section{Funding}

This research didn't receive any grant from any funding agency in the public, commercial or not-for-profit sectors.

\section{Authors' Contribution}

$D G F$ the corresponding author, worked on designing the study, training and supervising the data collectors, interpreting the result and preparing the manuscript. The co-authors namely $A B Y, E S C, A K W, S F T, G M W$, $A T W, T D, E M A, M M A, M A T, S S Y, E A L, B W D, H S H, S A A$ played their role in analyzing and interpreting the result. Moreover, the co-authors wrote the manuscript. All authors were involved in reading and approving the final manuscript.

\section{Acknowledgment}

The author acknowledged data collectors, and supervisors. The author is also deeply acknowledging Debre Tabor University. Last but not least, the respondents deserve sincere thanks for their kind responses.

\section{References}

1. Organization WH. Indicators for Assessing Infant and Young Child Feeding Practices, Part 1: Definitions. 2008. Geneva: World Health Organization; 2016.

2. Organization WH. Global strategy for infant and young child feeding. World Health Organization; 2003.

3. Monte $\mathrm{C}$, et al. Recommendations for the complementary feeding of the breastfed child. J Pediatr (Rio J). 2004;80(Suppl 5):131-41.

4. Organization WH. 2009. Infant and young child feeding: model chapter for textbooks for medical students and allied health professionals.

5. Food OA. The State of Food Insecurity in the World: How Does International Price Volatility Affect Domestic Economies and Food Insecurity? Publishing Policy: FAO Rome; 2011.

6. $\mathrm{Ng}$ CS. Complementary feeding indicators and determinants of poor feeding practices in Indonesia: a secondary analysis of 2007 Demographic and Health Survey data. Public Health Nutr. 2012;15(5):827-39.

7. Hotz C. Traditional food-processing and preparation practices to enhance the bioavailability of micronutrients in plant-based diets. J Nutr. 2007;137(4):1097-100.

8. Abeshu MA. Complementary feeding: review of recommendations, feeding practices, and adequacy of homemade complementary food preparations in developing countries-lessons from Ethiopia. Frontiers in nutrition. 2016;3:41.

9. Kimani-Murage EW. et al. Factors affecting actualisation of the WHO breastfeeding recommendations in urban poor settings in K enya. Maternal Child Nutrition. 2015;11(3):314-32.

10. Arts M,et al 2017. Improving the early initiation of breastfeeding: the WHO-UNICEF Breastfeeding Advocacy Initiative. Breastfeeding Medicine;12(6):326-7. 
11. Henry ME. Formula use in a breastfeeding culture: changing perceptions and patterns of young infant feeding in Vietnam. Johns Hopkins University; 2015.

12. White JM. Complementary feeding practices: Current global and regional estimates. Matern Child Nutr. 2017;13:e12505.

13. Mokori A. Child factors associated with complementary feeding practices in Uganda. South African Journal of Clinical Nutrition. 2017;30(1):7-14.

14. Nneka Christina, Okafoagu, et al, 2017. Factors influencing complementary and weaning practices among women in rural communities of Sokoto state, Nigeria.

15. JACOB. 2013. KIPRUTO KORIRDETERMINANTS OF COMPLEMENTARY FEEDING PRACTICES AND NUTRITIONAL STATUS OF CHILDREN 6-23 MONTHS OLD IN KOROGOCHO SLUM, NAIROBI COUNTY, KENYA.

16. Fatemeh, Abdollahi, et al. Study of Complementary Feeding Practices and Some Related Factors. among Mothers Attending Primary Health Centers; 2013.

17. Ethiopia Mini Demographic and Health Survey. (2019 EMDHS), 2019. neonatal mortality levels; child nutrition, and other health issues:20.

18. <Demographic Health Survey 2011 Ethiopia Final Report.pdf>. 2019.

19. Unicef. Programming guide: Infant and young child feeding. Nutr Sect UNICEF;173; 2011.

20. Demographic M. and Health Survey 2019 Key Indicators.

21. Disha A. Factors associated with infant and young child feeding practices. In: Amhara region and nationally in Ethiopia: analysis of the 2005 and 2011 demographic and health surveys. Washington, DC: Alive and Thrive; 2015.

22. Semahegn A, et al 2014. Complementary feeding practice of mothers and associated factors in Hiwot Fana Specialized Hospital, Eastern Ethiopia. The Pan African Medical Journal;18.

23. Dula A, et al, 2017. Complementary feeding practicesamong children in Benishangul Gumuz Region,Ethiopia.

24. Shikur, Mohammed, et al, 2018. Prevalence of initiation of complementary feeding at 6 months of age and associated factors among mothers of children aged 6 to 24 months in Addis Ababa, Ethiopia.

25. Belete $Y$, et al, 2017. Appropriate complementary feeding practice was relatively low and associated with mother's education, family income, and mother's age: a community based cross-sectional study in Northern Ethiopia Volume 6 Issue 2.

26. Desalegn Tsegaw, Hibstu, et al. Complementary feeding timing and its predictors among mothers' of children aged (6-23) months old in Halaba Kulito town, Southern Ethiopia. Curr Pediatr Res. 2018;22(1):61-8.

27. Kassa T,et al 2016. Appropriate complementary feeding practices and associated factors among mothers of children age 6-23 months in Southern Ethiopia, 2015. BMC pediatrics;16(1):131.

28. Ashenafi, Shumey, et al. Timely initiation of complementary feeding and associated factors among children aged 6 to 12 months in Northern Ethiopia: an institution-based cross-sectional study. BMC Public Health. 2013;13:1050. 
29. Tefera $\mathrm{C}$, et al. Initiation of complementary feeding and associated factors among children of age 6-23 months in Sodo town,Pediatric Reports. Vol. 9. Southern Ethiopia: Cross-sectional study; 2017. p. 7240.

30. Bereket, Yohannes, et al. Timely initiation of complementary feeding to children aged 6-23 months in rural Soro district of Southwest Ethiopia: a crosssectional study. BMC Pediatrics. 2018;18:17.

31. Muluye $D$, et al, 2012. Infant feeding practice and associated factors of HIV positive mothers attending prevention of mother to child transmission and antiretroviral therapy clinics in Gondar Town health institutions, Northwest Ethiopia. BMC public health;12(1):240.

32. Molla $\mathrm{M}$, et al. Complementary feeding practice and associated factors among mothers having children 6-23 months of age, Lasta District, Amhara region, Northeast Ethiopia. Advances in Public Health; 2017.

33. Tatiana 0, Vieira, et al, 2010. Determinants of breastfeeding initiation within the first hour of life in a Brazilian population: cross-sectional study.

34. Molla M, et al, 2017. Complementary Feeding Practice and Associated Factors among Mothers Having Children 6-23 Months of Age, Lasta District, Amhara Region, Northeast Ethiopia. Advances in Public Health:1-8.

35. Sisay $\mathrm{W}$, et al, 2015. Determinants of timely initiation of complementary feeding among mothers with children aged 6-23 months in Lalibela District, Northeast Ethiopia,. BMC public health. 2016;16(1):884.

36. Agumasie, Semahegn, et al. Complementary feeding practice of mothers and associated factors in Hiwot Fana Specialized Hospital. Eastern Ethiopia; 2014.

37. Ermyas Brhane, Reda, et al, 2019. Time to initiate complementary feeding and associated factors among mothers with children aged 6-24 months in Tahtay Maichew district, northern, Ethiopia.

38. Menberu Molla, et al. Complementary Feeding Practice and Associated Factors among Mothers Having Children 6-23 Months of Age. Lasta District, Amhara Region, Northeast Ethiopia; 2017.

39. Tigist, Kassa, et al. Appropriate complementary feeding practices and associated factors among mothers of children age 6-23 months in Southern Ethiopia. BMC Pediatrics. 2016;16:131.

40. UNICEF. Infant and young child feeding, nutrition section program. New York: UNICEF; 2012.

41. Rao S, Swathi P. 2011. Study of complementary feeding practices among mothers of children aged six months to two years-A study from coastal south India. The Australasian medical journal;4(5):252.

42. Katepa-Bwalya $M$, et al, 2015. Infants and young children feeding practices and nutritional status in two districts of Zambia. International breastfeeding journal;10(1):5.

43. Saaka M, et al, 2015. How well do WHO complementary feeding indicators relate to nutritional status of children aged 6-23 months in rural Northern Ghana? BMC public health;15(1):1157.

44. Manikam L, et al, 2018. Systematic review of infant and young child complementary feeding practices in South Asian families: the India perspective. Public health nutrition;21(4):637 - 54.

\section{Tables}


Table 1

Socio-demographic related variables of mothers who had children aged 6-23 months $(n=416)$ in Meket Woreda, Amhara, North east Ethiopia, June 2020 to December 2020.

\begin{tabular}{|c|c|c|c|}
\hline Variable & Categories & Frequency & Percentage \\
\hline \multirow[t]{4}{*}{ Marital status } & Single & 37 & 8.9 \\
\hline & Married & 350 & 84.1 \\
\hline & Divorced & 16 & 3.8 \\
\hline & Windowed & 13 & 3.1 \\
\hline \multirow[t]{3}{*}{ Mothers Religion } & Orthodox & 373 & 89.7 \\
\hline & Muslim & 37 & 8.9 \\
\hline & Protestant & 6 & 1.4 \\
\hline \multirow[t]{3}{*}{ Mothers ethnicity } & Amahra & 403 & 96.9 \\
\hline & Oromiya & 11 & 2.6 \\
\hline & Tigray & 2 & 0.5 \\
\hline \multirow[t]{5}{*}{ Mothers' educational status } & Unable to read and write & 123 & 29.6 \\
\hline & Able to read and write & 142 & 34.1 \\
\hline & Primary education & 40 & 9.6 \\
\hline & Secondary education & 31 & 7.5 \\
\hline & Diploma and above & 80 & 19.2 \\
\hline \multirow[t]{6}{*}{ Mothers' occupation } & Student & 15 & 3.6 \\
\hline & Housewife & 260 & 62.5 \\
\hline & Daily labor & 26 & 6.3 \\
\hline & Government employer & 84 & 20.2 \\
\hline & Private employer & 10 & 2.4 \\
\hline & Merchant & 21 & 5.0 \\
\hline \multirow[t]{5}{*}{ Husband educational status } & Unable to read and write & 102 & 24.5 \\
\hline & Able to read and write & 122 & 29.3 \\
\hline & Primary education & 40 & 9.6 \\
\hline & Secondary education & 30 & 7.2 \\
\hline & Diploma and above & 122 & 29.3 \\
\hline Monthly income (ETB) & $500-3000$ & 244 & 58.7 \\
\hline
\end{tabular}




\begin{tabular}{|llll|}
\hline Variable & Categories & Frequency & Percentage \\
\hline $3100-5600$ & 82 & 19.7 \\
\hline $5700-7200$ & 69 & 16.6 \\
\hline $7300-9800$ & 18 & 4.3 \\
\hline Sex of the children & $>9800$ & 3 & .7 \\
\hline Number of children & Female & 197 & 47.4 \\
\cline { 2 - 3 } & Male & 219 & 52.6 \\
& 1 & 166 & 39.9 \\
& $2-4$ & 209 & 50.2 \\
\hline & $>4$ & 41 & 9.9 \\
\hline
\end{tabular}

Table 2

Obstetric, and health related variables of mothers who had children aged 6-23months ( $n$ = 416) in Meket Woreda, Amhara, North east Ethiopia, June 2020 to December 2020.

\begin{tabular}{|llll|}
\hline Variable & Categories & Frequency & Percentage \\
\hline ANC follow-up & Yes & 305 & 73.3 \\
\cline { 2 - 4 } & No & 111 & 26.7 \\
\hline Number of antenatal care follow up visit & 1 & 51 & 12.3 \\
\cline { 2 - 4 } & $2-3$ & 120 & 28.8 \\
\cline { 2 - 4 } & $>3$ & 134 & 32.2 \\
\hline Place of delivery & Home & 146 & 35.1 \\
\cline { 2 - 4 } & Health facility & 270 & 64.9 \\
\hline Postnatal care & Yes & 248 & 59.6 \\
\cline { 2 - 4 } & No & 168 & 40.4 \\
\hline Number of postnatal care follow up & 1times & 90 & 21.6 \\
\cline { 2 - 4 } & 2-3times & 158 & 38.0 \\
\cline { 2 - 4 } & &
\end{tabular}


Table 3

Complementary feeding knowledge and practice of mothers who had children aged 6-23months $(n=416)$ in Meket Woreda, Amhara, North east Ethiopia, June 2020 to December 2020.

\begin{tabular}{|c|c|c|c|}
\hline Variable & Categories & Frequency & Percentage \\
\hline \multirow[t]{2}{*}{ Did you breast feeding initiate for your child } & Yes & 345 & 82.9 \\
\hline & No & 71 & 17.1 \\
\hline \multirow[t]{2}{*}{ Did you breast feeding exclusively } & Yes & 345 & 82.9 \\
\hline & No & 71 & 17.1 \\
\hline \multirow[t]{2}{*}{ Have you ever heard about when start CF } & Yes & 332 & 79.8 \\
\hline & No & 84 & 20.2 \\
\hline \multirow[t]{7}{*}{ When to start complimentary feeding for your child } & At 1 month & 3 & 0.7 \\
\hline & 2 month & 2 & 0.5 \\
\hline & 4 month & 1 & 0.2 \\
\hline & 5 month & 1 & 0.2 \\
\hline & 6 month & 318 & 76.4 \\
\hline & 7 month & 3 & 0.7 \\
\hline & 8 month & 5 & 1.2 \\
\hline \multirow{2}{*}{$\begin{array}{l}\text { Have you started CF (initiate)at } 6 \text { month of age for your } \\
\text { child }\end{array}$} & Yes & 302 & 72.6 \\
\hline & No & 113 & 27.2 \\
\hline \multirow{4}{*}{$\begin{array}{l}\text { What do you think common kind of food introduced first } \\
\text { time to feed child }\end{array}$} & Soup & 62 & 14.9 \\
\hline & Cow milk & 139 & 33.4 \\
\hline & Forage & 212 & 51.0 \\
\hline & Other & 2 & 0.5 \\
\hline \multirow[t]{7}{*}{ What type of foods are feed to the child } & Cereal & 176 & 42.3 \\
\hline & Legumes & 38 & 9.1 \\
\hline & Milk product & 134 & 32.2 \\
\hline & Meat ,fish, chicken & 10 & 2.4 \\
\hline & Egg & 34 & 8.2 \\
\hline & $\begin{array}{l}\text { Other fruit and } \\
\text { vegetable }\end{array}$ & 17 & 4.1 \\
\hline & honey, sugar, & 3 & 0.7 \\
\hline
\end{tabular}




\begin{tabular}{|lllc|}
\hline Variable & Categories & Frequency & Percentage \\
\hline & Butter oil & 3 & 0.7 \\
\cline { 2 - 4 }
\end{tabular}


Table 4

Attitude of Mothers towards Complementary Infant Feeding who had children aged 6-23 months $(n=416)$ in Meket Woreda, Amhara, North east Ethiopia, June 2020 to December 2020.

\begin{tabular}{|c|c|c|c|c|c|c|c|c|c|c|c|c|}
\hline \multirow{2}{*}{$\begin{array}{l}\text { S.N } \\
0\end{array}$} & \multirow{2}{*}{ Statement } & \multicolumn{2}{|l|}{ SA } & \multicolumn{2}{|l|}{ A } & \multicolumn{2}{|l|}{ DK } & \multicolumn{2}{|l|}{ D } & \multicolumn{2}{|c|}{$S D$} & \multirow[t]{2}{*}{ Mean* } \\
\hline & & No & $\%$ & No & $\%$ & No & $\%$ & No & $\%$ & No & $\%$ & \\
\hline 1 & $\begin{array}{l}\text { I provide } \\
\text { complementary } \\
\text { foods because } \\
\text { it makes my } \\
\text { infant fat }\end{array}$ & 94 & 22.6 & 29 & 6.9 & 108 & 26 & 126 & 30.3 & 59 & 14.2 & 3.07 \\
\hline 2 & $\begin{array}{l}\text { I have enough } \\
\text { money to buy } \\
\text { complementary } \\
\text { food items } \\
\text { instead of } \\
\text { suffering } \\
\text { myself by } \\
\text { breast feeding }\end{array}$ & 25 & 6 & 64 & 15.3 & 129 & 31 & 165 & 39.7 & 33 & 7.9 & 3.28 \\
\hline 3 & $\begin{array}{l}\text { My breast milk } \\
\text { is not sufficient } \\
\text { to my infant so } \\
\text { just after birth I } \\
\text { like to } \\
\text { introduce } \\
\text { complementary } \\
\text { foods to my }\end{array}$ & 82 & 19.7 & 160 & 38.4 & 77 & 18.5 & 74 & 17.8 & 23 & 5.5 & 2.51 \\
\hline 4 & $\begin{array}{l}\text { Since others } \\
\text { can help me by } \\
\text { providing } \\
\text { complementary } \\
\text { foods I like it }\end{array}$ & 117 & 28.1 & 149 & 35.8 & 65 & 15.6 & 65 & 15.6 & 20 & 4.8 & 2.33 \\
\hline 5 & $\begin{array}{l}\text { Breast feeding } \\
\text { makes my } \\
\text { appearance } \\
\text { thin so I like to } \\
\text { give } \\
\text { complementary } \\
\text { foods to my } \\
\text { infant }\end{array}$ & 78 & 18.8 & 61 & 14.6 & 128 & 30.8 & 113 & 27.2 & 36 & 8.7 & 2.93 \\
\hline 6 & $\begin{array}{l}\text { Providing my } \\
\text { infant with } \\
\text { complementary } \\
\text { foods make } \\
\text { him/her } \\
\text { healthy and } \\
\text { strong }\end{array}$ & 211 & 50.7 & 85 & 20.4 & 34 & 8.2 & 46 & 11.1 & 40 & 9.6 & 2.08 \\
\hline
\end{tabular}

Key: "SA" stands for Strongly Agree "A" for Agree "DK" for Don't Know " D" for Disagree "SD" for Strongly Disagree 


\begin{tabular}{|c|c|c|c|c|c|c|c|c|c|c|c|c|}
\hline \multirow{2}{*}{$\begin{array}{l}\text { S.N } \\
0\end{array}$} & \multirow{2}{*}{ Statement } & \multicolumn{2}{|l|}{ SA } & \multicolumn{2}{|l|}{ A } & \multicolumn{2}{|l|}{ DK } & \multicolumn{2}{|l|}{ D } & \multicolumn{2}{|l|}{ SD } & \multirow[t]{2}{*}{ Mean* } \\
\hline & & No & $\%$ & No & $\%$ & No & $\%$ & No & $\%$ & No & $\%$ & \\
\hline 7 & $\begin{array}{l}\text { After six } \\
\text { months in } \\
\text { addition of } \\
\text { breast feeding } \\
\text { complementary } \\
\text { foods are } \\
\text { preferable. }\end{array}$ & 71 & 17.1 & 65 & 15.6 & 105 & 25.2 & 103 & 24.8 & 72 & 17.3 & 3.1 \\
\hline $\begin{array}{l}\text { Key } \\
\text { Disa }\end{array}$ & $A^{\prime \prime}$ stands for St & & ee "A" & & "DK' & & & & & & & nngly \\
\hline
\end{tabular}


Table 5

Multivariable Logistic regression analysis of factors associated with initiation of complementary feeding at 6 months of age among mothers of children aged 6-24 months $(n=416)$ in Meket Woreda, Amhara, North east Ethiopia, June 2020 to December 2020.

\begin{tabular}{|c|c|c|c|c|c|}
\hline \multirow[t]{2}{*}{ Explanatory variable } & \multirow[t]{2}{*}{ Category } & \multicolumn{2}{|c|}{$\begin{array}{l}\text { Initiation of CF at } 6 \\
\text { month }\end{array}$} & \multicolumn{2}{|c|}{ Adjusted OR $(95 \% \mathrm{Cl})$} \\
\hline & & yes & no & $(95 \% \mathrm{Cl})$ & $\begin{array}{l}\mathrm{P}- \\
\text { value }\end{array}$ \\
\hline \multirow[t]{2}{*}{$\begin{array}{l}\text { Advised About CF during ANC } \\
\text { follow up }\end{array}$} & no & $61(50.8 \%)$ & $59(49.2 \%)$ & $\begin{array}{l}0.030(0.003 \\
0.356)\end{array}$ & \multirow[t]{2}{*}{0.005} \\
\hline & yes & $241(81.7 \%)$ & $55(18.3 \%)$ & 1 & \\
\hline \multirow[t]{2}{*}{$\begin{array}{l}\text { Child delivered place at a health } \\
\text { facility }\end{array}$} & Home & $85(58.6 \%)$ & $61(41.4 \%)$ & $\begin{array}{l}0.07(0.0 \\
0.619)\end{array}$ & \multirow[t]{2}{*}{0.03} \\
\hline & $\begin{array}{l}\text { At a health } \\
\text { facility }\end{array}$ & $217(80.4 \%)$ & $53(19.6 \%)$ & 1 & \\
\hline \multirow[t]{2}{*}{ family planning } & No & $59(53.2 \%)$ & $53(46.8 \%)$ & $\begin{array}{l}0.09(0.011 \\
0.23)\end{array}$ & \multirow[t]{2}{*}{$\stackrel{\leq}{0.001}$} \\
\hline & Yes & $\begin{array}{l}243 \\
(79.9 \%)\end{array}$ & $\begin{array}{l}61 \\
(20.1 \%)\end{array}$ & 1 & \\
\hline \multirow[t]{2}{*}{$\begin{array}{l}\text { give additional diet the 1st } \\
6 \text { month }\end{array}$} & no & $53(39.0 \%)$ & $\begin{array}{l}84 \\
(61.0 \%)\end{array}$ & $\begin{array}{l}0.035(0.009 \\
0.137)\end{array}$ & \multirow[t]{2}{*}{$\stackrel{\leq}{0.001}$} \\
\hline & yes & $249(89.2 \%)$ & $30(10.8 \%)$ & 1 & \\
\hline \multirow[t]{5}{*}{$\begin{array}{l}\text { Breast feeding makes } \\
\text { appearance }\end{array}$} & Agree Disagree & $19(52.8 \%)$ & $17(47.2 \%)$ & $\begin{array}{l}0.064(0.003 \\
0.687)\end{array}$ & 0.041 \\
\hline & Disagree & $85(75.2 \%)$ & $28(24.8 \%)$ & $\begin{array}{l}0.03(0.05 \\
0.90)\end{array}$ & 0.01 \\
\hline & Don't Know & $88(68.8 \%)$ & $40(31.2 \%)$ & $\begin{array}{l}0.04(0.009 \\
1.50)\end{array}$ & $\begin{array}{l}\leq \\
0.001\end{array}$ \\
\hline & Agree & $50(83.3 \%)$ & 11(16.7\%) & $\begin{array}{l}0.001(0.00 \\
0.87)\end{array}$ & 0.21 \\
\hline & $\begin{array}{l}\text { Strongly } \\
\text { Strongly }\end{array}$ & $60(76.9 \%)$ & $\begin{array}{l}18 \\
(23.1 \%)\end{array}$ & 1 & \\
\hline
\end{tabular}

\section{Figures}




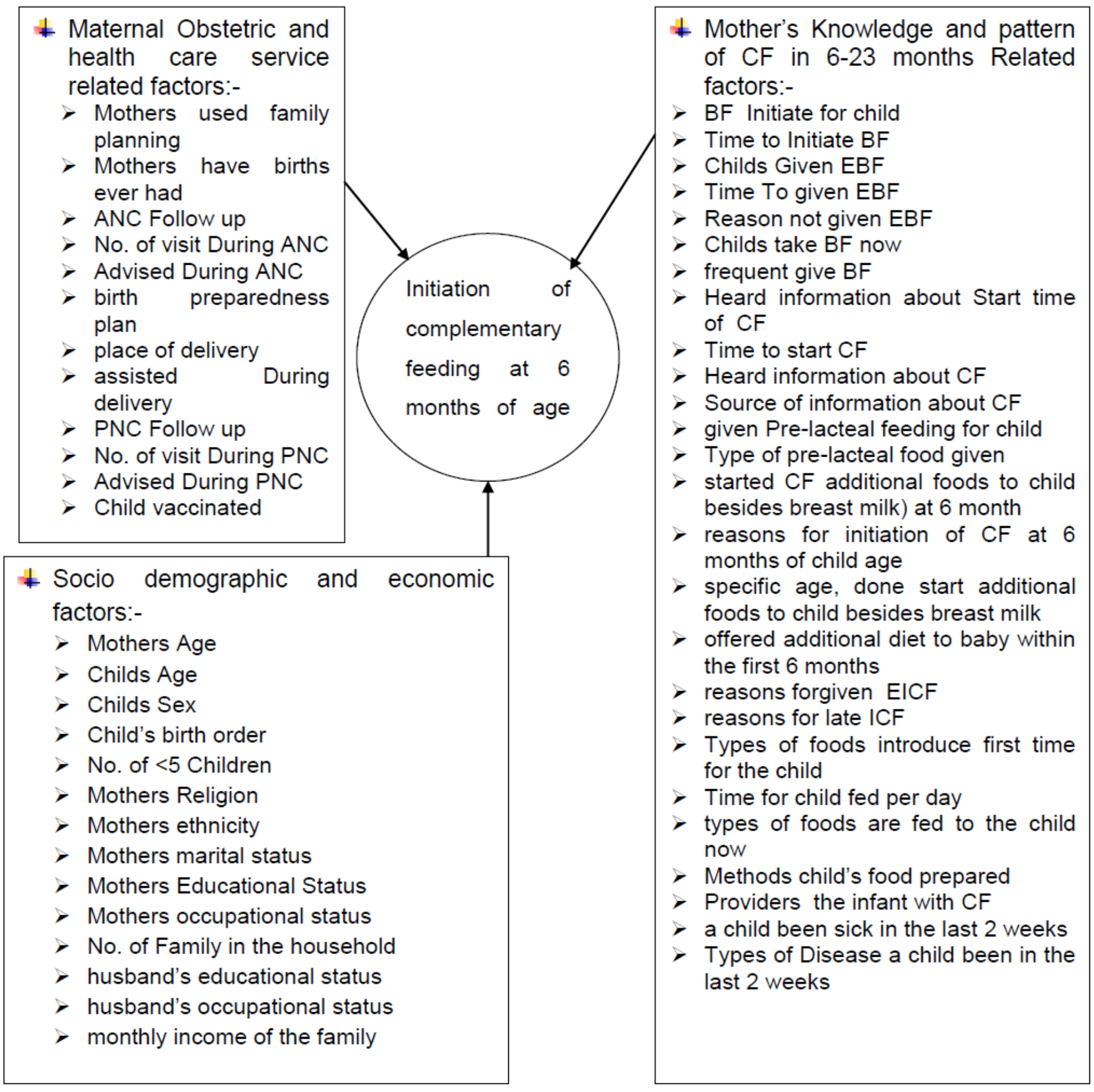

Figure 1

Conceptual framework for the study on Initiation of complementary feeding practice and associated factors among mothers having children 6-23 month of age, in Meket Woreda, North Wollo Ethiopia, 2020 (Adapted in different Articles(19, 22, 24, 27-30, 32, 35-39). 


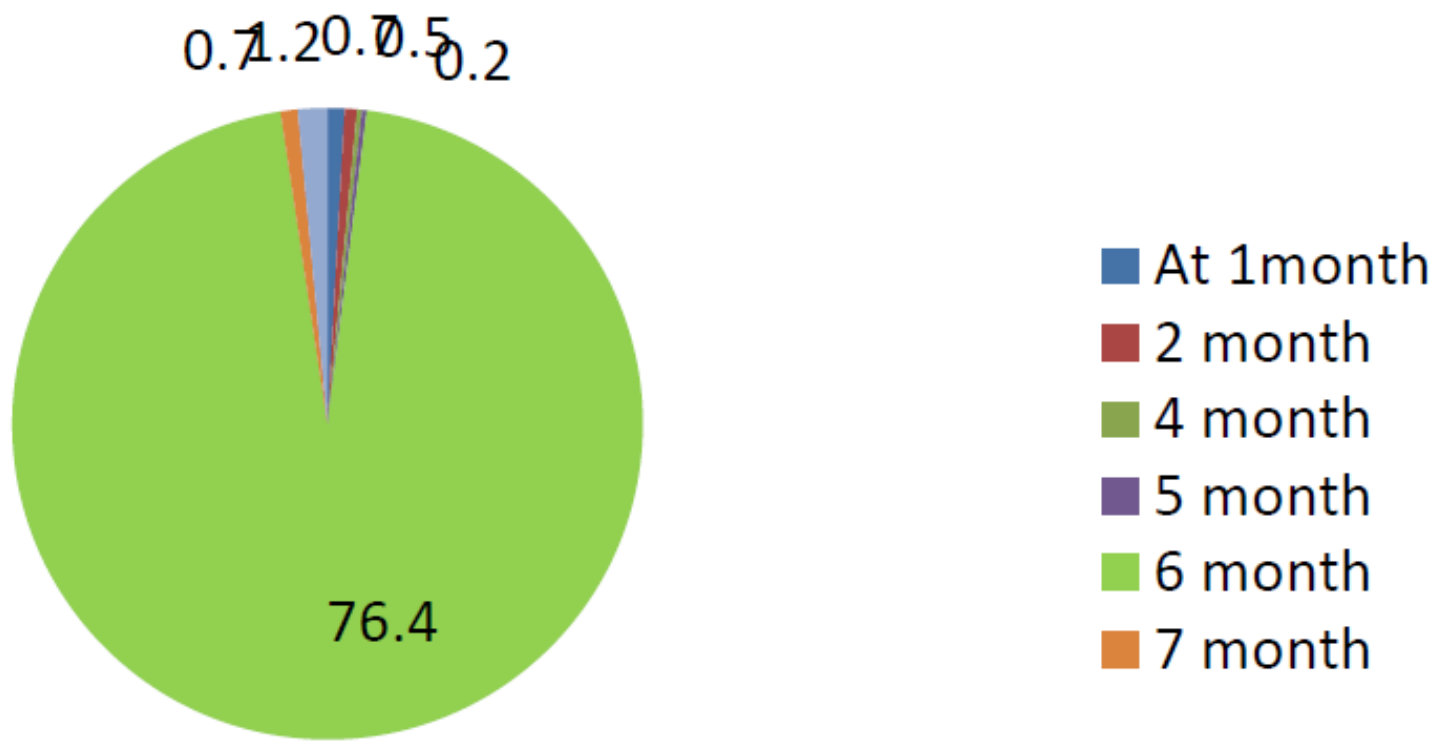

Figure 2

Time at which complementary feeding was initiated by of mothers who had children aged $6-23$ months ( $n=$ 416) in Meket Woreda, Amhara, North east Ethiopia, June 2020 to December 2020.

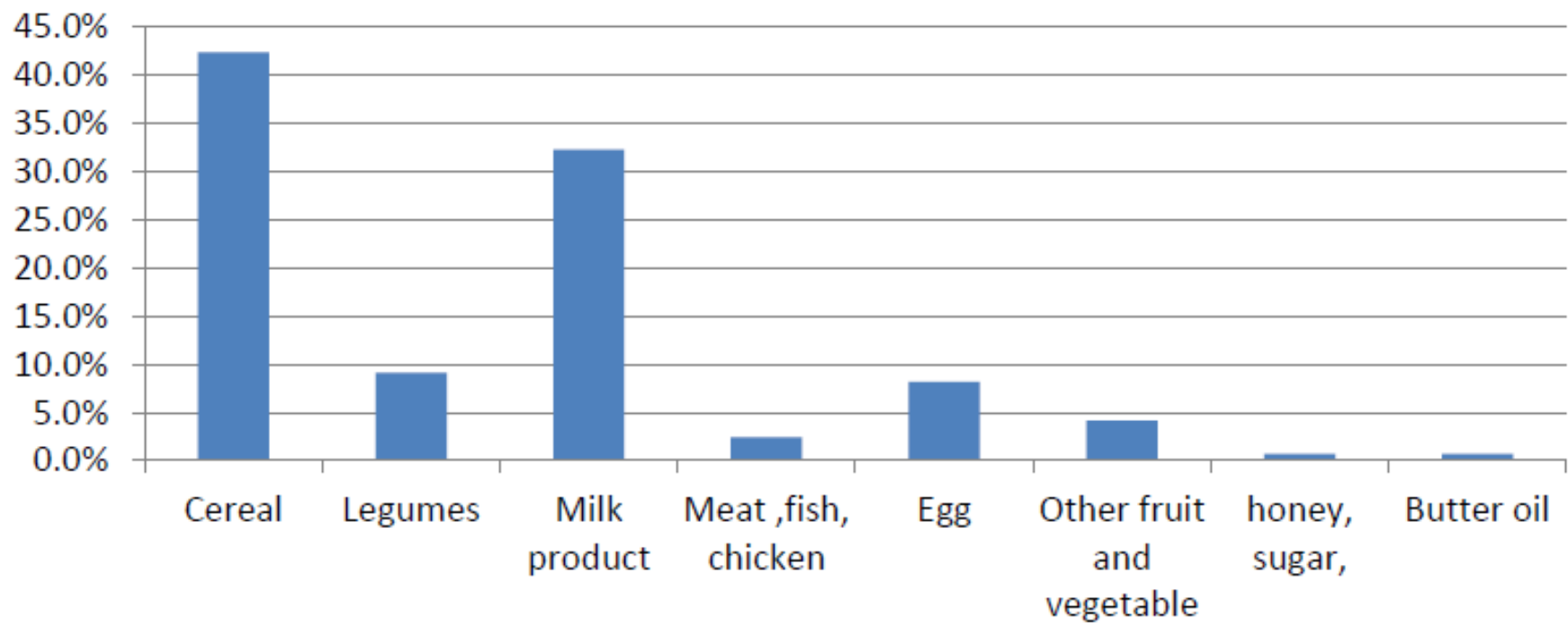

Figure 3

Types of food initiated as complementary food of mothers who had children aged 6-23months $(n=416)$ in Meket Woreda, Amhara, North east Ethiopia, and June 2020 to December 2020. 